\title{
Effects of aqueous extract of polyherbal formulation against hyperthyroidism induced by L-thyroxin in a rat model
}

\author{
Sahar B. Ahmed ${ }^{1}$, Asmaa M. Moghazy2 ${ }^{2}$, Omar A. Ahmed-Farid ${ }^{3},{ }^{\circ}$, , Hassan A. Esebery ${ }^{4}$
}

${ }^{1}$ Department of Biochemistry, National Organization for Drug Control and Research (NODCAR)

${ }^{2}$ Department of Hormonal Evaluation, National Organization for Drug Control and Research (NODCAR)

${ }^{3}$ Department of Physiology, National Organization for Drug Control and Research (NODCAR)

${ }^{4}$ Department of Histology, National Organization for Drug Control and Research (NODCAR)

\section{Correspondence}

Omar A. Ahmed-Farid, Department of Physiology, National Organization for Drug Control and Research (NODCAR)

Email: ebntaimya@yahoo.com

History

- Received: 13 June 2018

- Accepted: 18 November 2018

- Published: 10 December 2018

DOI :

https://doi.org/10.15419/bmrat.v5i12.506

\section{Check for updates}

\section{Copyright}

(c) Biomedpress. This is an openaccess article distributed under the terms of the Creative Commons Attribution 4.0 International license.

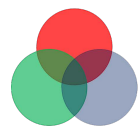

BioMedPress

The Open Access Publisher

\begin{abstract}
Background: Hyperthyroidism is a disorder that occurs when the thyroid gland secretes more thyroid hormone than the body needs. Thyroid hormone is essential for the normal growth and development of normal organs. Polyherb $(\mathrm{POH})$ formulation has proven to be useful in number of diseases and has been used in folk medicine as an anti-hyperthyroidism, anti-oxidant, and appetitestimulating agent. The aim of the study was to evaluate the curative effect of POH against L-thyroxin $\left(\mathrm{LT}_{4}\right)$-induced hyperthyroidism in male rats. Methods: Seven groups (10 rats each) were used for this purpose. Determination of phytochemical analysis, oxidative stress markers, brain appetite marker and cell energy marker were determined via high-performance liquid chromatography (HPLC) techniques. Thyroid hormones were detected via ELISA, and liver functions were determined by colorimetric method. Results: The data showed that $\mathrm{LT}_{4}$ altered thyroid function via decreasing serum Thyroid-stimulating hormone (TSH), serum total protein, albumin and globulin, while increasing Triiodothyronine (T3), Thyroxine (T4), and Aspartate aminotransferase (AST). Moreover, oxidative stress markers in liver tissues were increased, via up-regulation of nitric oxide (NO), oxidized glutathione (GSSG), malondialdehyde (MDA), and 8-hydroxy-2'-deoxyguanosine (8OHdG). Meanwhile, glutathione (GSH) and ATP were alleviated; in contrast, metabolites of ADP and AMP were elevated. Neuronal appetite marker in brain tissue was decreased via low serotonin levels. On the other hand, rat groups treated with $\mathrm{POH}$ and Carbimazole (CBZ) showed markedly amelioration of hyperthyroidism in rats at low dose only but did not show complete amelioration at high dose of $\mathrm{POH}$. The data were confirmed through histopathological examination of the thyroid. Conclusion: The data obtained demonstrated that $\mathrm{POH}$, at low dose, can be very effective for completely treating hyperthyroidism in rats, and was safer than Carbimazole (CBZ) and ameliorated most signaling pathways and in different tissues.

Key words: Carbimazole, Hyperthyroidism, Poly herb, T3, T4, TSH
\end{abstract}

\section{INTRODUCTION}

The thyroid gland is an important part of the human endocrine system, which is responsible for regulation of oxygen use, basal metabolic rate, cellular metabolism, growth and development ${ }^{1}$. The thyroid gland secretes 3 hormones- thyroxin (T4), triiodothyronine (T3) and calcitonin- which are needed for proper growth and development. The thyroid hormones are transported through the blood and act at the cellular level. Through the activation of genes, thyroid hormones stimulate protein synthesis, promote maturation of the nervous system, and increase the rate of cell respiration in tissue ${ }^{2}$.

The thyroid gland plays a major role in regulating the body's metabolic processes. Thus, any dysfunction of the endocrine gland would mean that all the human organs were dysfunctional. Thyroid disorders generally fall under three categories: hyperthyroidism, hypothyroidism and hyperplasia of the thyroid. Although some clinical studies did not show any evidence of treating thyroid cases using conventional herbal medicines, these herbs have contributed to low excitement rates, relieved some adverse effects, relieved symptoms, and improved thyroid function ${ }^{2}$. The increase in thyroid activity is known as hyperthyroidism (HT), and is often caused by Graves' disease. HT involves an increase of the secretion of thyroxin, a hormone in the blood that regulates the metabolism of cells in the body. Thyroxin plays an important role in the safety of the thyroid gland itself and the presence of iodine, which is regulated by production of thyroid stimulating hormone (TSH) by the pituitary gland in the brain ${ }^{3}$. Hyperthyroidism occurs due to malfunction of the pituitary gland, which regulates thyroid function; over-activity of the thyroid gland and imbalance (overproduction) of hormone production from the thyroid can occur, leading to higher thyroxin level in the blood. The main symptoms of hyperthyroidism are loss of weight, irregular heartbeat, increased rate of metabolism, lack

Cite this article : Ahmed S B, Moghazy A M, Ahmed-Farid O A, Esebery H A. Effects of aqueous extract of polyherbal formulation against hyperthyroidism induced by L-thyroxin in a rat model. Biomed. Res. Ther.; 5(12):2876-2887. 
of sleep, and high blood pressure. Hyperthyroidism can also cause disturbances in bowel movement, irregular menstrual cycle, anxiety, hand tremor and excessive sweating ${ }^{4}$. Carbimazole (CBZ) is one of several thionamide drugs used in the treatment of hyperthyroidism. It works by inhibiting the thyroid peroxidases (TPO) that catalyze the iodination of tyrosine residues in thyroglobulin and the oxidative coupling of iodinated tyrosine ${ }^{5}$. CBZ is a good medication but has many side effects, such as digestion disorder, reduction of white blood cells, nausea, headache, rash, and itching. CBZ has many precautions when taking with other medicine; it acts as an anti-vitamin $\mathrm{K}$ so it may strengthen the anticoagulant effect ${ }^{6}$. Herbs and herbal products have been recommended to promote healthy thyroid regulation. Medicinal plants and natural products represent one of the most popular alternative treatments. Herbal medicines are known to act synergistically in combination. Polyherbal (POH) formulation is composed of Thymus vulgaris, Origanum majorane, Foeniculum vulgare, Anethum graveolens, Saussurea costus, and Matricaria chamomilla.

The objective of this study was to evaluate the curative effect of an aqueous extract of $\mathrm{POH}$ against hyperthyroidism induced by L-thyroxin $\left(\mathrm{LT}_{4}\right)$ and compared with $\mathrm{CBZ}$ as an anti-thyroid drug ${ }^{7}$.

\section{METHODS}

\section{Reagents}

All chemicals, solvents and reagents were of highperformance liquid chromatography (HPLC) grade and purchased from Sigma-Aldrich (St. Louis, MO, USA). All herbs were purchased from local markets and authenticated at the Faculty of Agriculture, Cairo University.

\section{Experimental animals}

One hundred male rats (weight of $180 \pm 20 \mathrm{~g}$ ) were obtained from the National Organization for Drug Control and Research (NODCAR), Giza, Egypt for use in this study. The rats were housed in wire mesh fence cages under standard conditions (temperature $25 \pm 2^{\circ} \mathrm{C}$, with $12 \mathrm{~h}$ light and $12 \mathrm{~h}$ darkness cycles). Animals were fed standard pellet rat diet and water ad libitum. The study was conducted in accordance to the recommendations from the Declaration of Helsinki on guiding principles of care and use of animals.

\section{Extract preparation}

Six aqueous extracts of $\mathrm{POH}$ were used in the treatment of HT induced by $\mathrm{LT}_{4}$ for two weeks prior to treatments. Approximately $1,500 \mathrm{~g}$ of $\mathrm{POH}$, consistent with an equivalent weight of 6 aqueous extracts (Thymus vulgaris, Origanum majorane, Foeniculum vulgare, Anethum graveolens,Saussurea costus and Matricaria chamomilla), were placed in a clean, flatbottomed glass container and soaked in ten volume of distilled water. The container (with its contents) was sealed and kept for 3 days, and then the extraction was carried out. The content was filtrated through a piece of clean, white cotton material. The extract was then filtered through Whatman filter paper (Bibby RE200, Sterilin Ltd., UK). The gummy extract was stored at $20^{\circ} \mathrm{C}$ until chromatographic separation by HPLC, gas chromatography-mass spectrometry (GCMS), and in vivo examination.

\section{Chromatographic analysis}

All chemical constituents of POH for HPLC analysis were determined according to Nogata et al. ${ }^{8}$ and Wang et al. ${ }^{9}$. GCMS analysis was determined according to Tokuşoğlu et al. ${ }^{10}$.

\section{Experimental design}

The experimental design was carried out for two experiments as follows:

The $1^{\text {st }}$ experiment was designed to determine $\mathrm{LD}_{50}$. Thirty adult male rats ( $\mathrm{n}=5$ per group) were treated with different doses of $\mathrm{POH}$ (9000, 7500, 5000, 3000, and $1500 \mathrm{mg} / \mathrm{kg}$ b.w.), respectively. Indeed, in all the experiments all doses were deemed safe and did not lead to any mortality. The dose was derived as $1 / 10$ and $1 / 20$ of the maximum dose of the $1^{\text {st }}$ experiment. The $2^{\text {nd }}$ experiment was designed as a biological study. Seventy rats were assigned into 7 groups $(n=10$ per group):

- Group 1 consisted of normal control rats that received distilled water (control; “C”);

- Group 2 ("HT” group) was treated with $\mathrm{LT}_{4}(100$ $\mathrm{mg} / \mathrm{kg}$ b.w.);

- Group 3 was treated with $\mathrm{LT}_{4}$ (to induce $\mathrm{HT}_{\text {) }}$ plus low dose of POH (450 mg/kg b.w.), and called "HT + LPOH";

- Group 4 was treated with $\mathrm{LT}_{4}+$ high dose of $\mathrm{POH}$

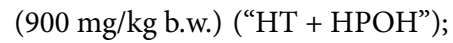

- Group 5 was treated with $\mathrm{LT}_{4}+\mathrm{CBZ}(0.450 \mathrm{mg} / \mathrm{kg}$ b.w.) ("HT + CBZ");

- Group 6 was treated with low dose $\mathrm{POH}(450$ $\mathrm{mg} / \mathrm{kg}$ b.w.) (“LPOH”); and

- Group 7 was treated with high dose of $\mathrm{POH}(900$ $\mathrm{mg} / \mathrm{kg}$ b.w.) (“HPOH”).

All the administrations were given via oral intubation and the experiments were maintained for 6 weeks. 


\section{Blood and tissue collections}

At the end of the experiment, blood samples were collected from the orbital plexus veins and then the rats were sacrificed by cervical dislocation. Serum was separated and stored at $-20{ }^{\circ} \mathrm{C}$ until analysis of $\mathrm{TSH}^{11}, \mathrm{~T} 3$ and $\mathrm{T} 4{ }^{12}$, Aspartate aminotransferase (AST) and Alanine aminotransferase (ALT) ${ }^{13}$, Total protein $(\mathrm{TP})^{14}$, and Albumin $(\mathrm{Alb})^{15}$. Globulin and $\mathrm{A} / \mathrm{G}$ ratio were calculated.

\section{Tissue collection}

Liver and brain tissues were taken at the end of the experiment to determine the antioxidant levels of malondialdehyde (MDA) in nmol/g tissue by HPLC according to Karatepe et al. ${ }^{16}$. Reduced glutathione (GSH) and oxidized glutathione (GSSG) content were determined by HPLC, according to Jayatilleke and Shaw et al. ${ }^{17}$, and level of nitric oxide (NO) was determined using HPLC, according to Papadoyannis et al. ${ }^{18}$. The level of 8-hydroxy-2' -deoxyguanosine (8-OHdG) was determined by HPLC, according to Lodovici et al. ${ }^{19}$. Determination of cell energy content of adenosine triphosphate (ATP), adenosine diphosphate (ADP), and adenosine monophosphate (AMP) was conducted by HPLC, according to Teerlink et al. ${ }^{20}$, and the determination of serotonin (5$\mathrm{HT}$ ) was determined in brain tissue, according to Pagel et al. ${ }^{21}$.

\section{Histopathological examination}

Thyroid samples were taken from the thyroid gland of rats of the different groups and fixed in $10 \%$ neutral buffered formalin for $24 \mathrm{~h}$. Washing was done in tap water then serial dilutions of alcohol were used for dehydration. Specimens were cleared in xylene and embedded in paraffin at $56{ }^{\circ} \mathrm{C}$ in a hot air oven for 24 h. Paraffin-embedded tissue blocks were prepared for sectioning $4 \mu \mathrm{m}$ slices onto slides using a microtome. The obtained tissue sections were collected onto glass slides, de-paraffinized and stained by Hematoxylin \& Eosin, according to Banchroft et al. ${ }^{22}$, for histopathological examination through a light microscope.

\section{Statistical analysis}

The values were expressed as the mean \pm SE for the 10 rats in each group. Differences between groups were assessed by one way analysis of variance (ANOVA) using the SAS statistical software (SAS Institute, Cary, North Carolina, USA). Statistical analysis of the obtained data was performed using the general linear model (GLM). Significant differences among means were evaluated using Duncan's Multiple Range Test.

\section{RESULTS}

Table 1 shows the HPLC chromatogram of the aqueous extract of $\mathrm{POH}$; the HPLC chromatograms indicate the presence of Ascorbic acid, Caffeic acid, Cinnamic acid, Ellagic acid, and Valinic acid (Figure 1) as well as Rutin and Epigallocatechin gallate (Figure 2), all of which can be seen at different concentrations. Ferulic acid, Gallic acid, Apigenin 7-O$\beta$-D-glucoside, Bisabolol, Costunolide, Dillapiole, Kaempferol, Quercetin and Thymol were also present in different concentrations. Table 2 and Figure 3illustrated the G-CMS chromatogram of the aqueous extract of $\mathrm{POH}$, and indicated the presence of Apigenin 7-O- $\beta$-D-glucoside, Bisabolol, Costunolide, Dillapiole, Kaempferol, Quercetin and Thymol at different concentrations.

The results of Table 3 showed that $\mathrm{LT}_{4}$-treated rats exhibited HT, with a significant decrease $(\mathrm{p}<0.05)$ of TSH from the actual mean (of $0.326 \pm 0.021$ ). Meanwhile, the level of T3 and T4 were significantly increased in serum of treated rats; the means were 2.929 \pm 0.141 , and $128.7 \pm 7.88 \mathrm{ng} / \mathrm{dL}$, respectively, compared to those levels in the control group (1.727 \pm $0.078 ; 74.5 \pm 5.66)$. Treatment with low and high dose of $\mathrm{POH}$ (or $\mathrm{CBZ}$ as reference drug) in our rat model of HT showed that there was an adapted thyroid alteration through an increase of TSH and decrease of T3 and T4, in comparison with the LT-4 group. The actual means ofLT4+LPOH for TSH, T4, T3 then LT4+HPOH, LT4+CBZ were $0.545 \pm 0.051$, $1.877 \pm 0.195,79.7 \pm 6.21,0.564 \pm 0.034,1.99 \pm$ $0.119,85.6 \pm 5.69,0.541 \pm 0.046,1.803 \pm 0.173,70.7$ \pm 3.84 , respectively. Meanwhile, normal rats treated with $\mathrm{LPOH}$ and $\mathrm{HPOH}$ caused a significant increase in T3 with an actual mean of $84 \pm 7.98$ and $91.3 \pm$ 1.37, respectively, for $\mathrm{LPOH}$ and $\mathrm{HPOH}$.

Table 4 illustrates that after 2 weeks of $\mathrm{LT}_{4}$ injection, in the serum there was disrupted liver protein production and instigation of hepatocyte disruption via infiltrating liver enzymes; the actual means were 58.1 $\pm 1.60,31.7 \pm 0.48,6.3 \pm 0.17,3.3 \pm 0.08,3.0 \pm 0.08$, $1.10 \pm 0.023$, respectively $v s$. the control group (51.0 $\pm 1.47,27.6 \pm 0.74,7.8 \pm 0.20,3.7 \pm 0.10,4.1 \pm$ $0.11,0.90 \pm 0.025$, respectively). In contrast, $\mathrm{LPOH}$, $\mathrm{HPOH}$ and $\mathrm{CBZ}$ ameliorate liver protein production especially TP and Glob, with actual means of $7.7 \pm$ $0.21,7.6 \pm 0.20,8.0 \pm 0.21,3.9 \pm 0.10,4.0 \pm 0.10,3.8$ \pm 0.10 , respectively. On the contrary, $\mathrm{HPOH}$ showed a marked increase of liver enzymatic infiltration via serum AST (mean of $76.7 \pm 2.14$, vs. control group). The data shown in Table 5 showed that the HT model via $\mathrm{LT}_{4}$ induction stimulates nitrositive radicals and 
Table 1: Phenolic compounds content of aqueous extract of POH by HPLC

\begin{tabular}{lc}
\hline Phenolic components & Concentration $\mu \mathbf{g} / \mathbf{g}$ died powder \\
Ascorbic acid & 0.425 \\
Caffic acid & 1.353 \\
Cinnamic acid & 1.569 \\
Ellagic acid & 0.048 \\
Ferulic acid & 0.011 \\
Gallic acid & 0.501 \\
Valinic acid & 1.377 \\
Epigallocatechin gallate & 0.553 \\
Rutin & 1.814 \\
Apigenin-7-O- $\beta$ - & 0.919 \\
Dglucoside & \\
Bisabolol & 1.924 \\
Costunolide & 0.337 \\
Dillapiole & 2.059 \\
Kaempferol & 1.580 \\
Quercetin & 0.403 \\
Thymol & 1.587 \\
\hline
\end{tabular}

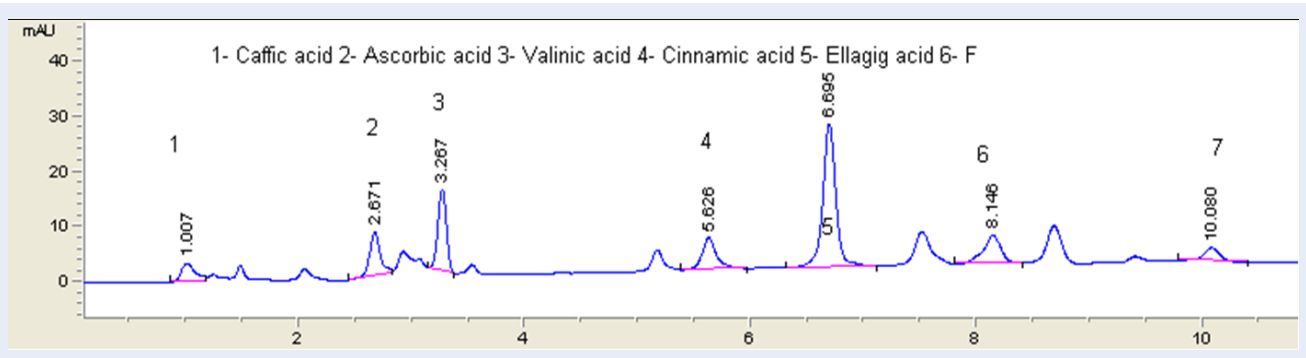

Figure 1: HPLC Chromatogram of aqueous extract of POH (Caffeic acid, ascorbic acid, Valinic acid, Cinnamic acid and Ellagic Acid).

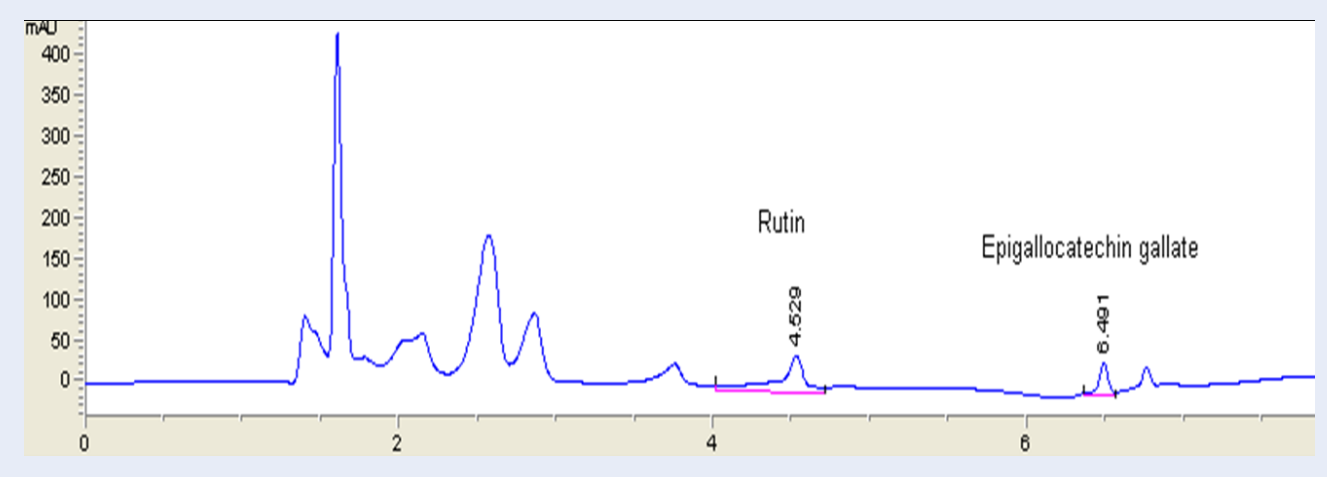

Figure 2: HPLC Chromatogram of aqueous extract of POH (Rutin and Epigallocatechin gallate). 
Table 2: Phenolic compounds content of $\mathrm{POH}$ aqueous extract by G-CMS

\begin{tabular}{lc}
\hline Phenolic components & Concentration $\mu \mathbf{g} / \mathbf{g}$ died powder \\
Apigenin-7-O- $\beta$ - & 0.919 \\
Dglucoside & \\
Bisabolol & 1.924 \\
Costunolide & 0.337 \\
Dillapiole & 2.059 \\
Kaempferol & 1.580 \\
Quercetin & 0.403 \\
Thymol & 1.587 \\
\hline
\end{tabular}

Table 3: Effects of LPOH, HPOH and CBZ (as reference drug) on thyroid hormonal profile in hyperthyroidism rat model

\begin{tabular}{lccc}
\hline $\begin{array}{l}\text { Parameter Animal } \\
\text { Groups }\end{array}$ & TSH (IU/ml) & T4 (ng/dl) & T3 (ng/dl) \\
Control & $0.521 \pm 0.033$ & $1.727 \pm 0.078$ & $74.5 \pm 5.66$ \\
LPOH & $0.604 \pm 0.057$ & $2.012 \pm 0.218$ & $84 \pm 7.98^{a}$ \\
HPOH & $0.580 \pm 0.019$ & $2.141 \pm 0.066$ & $91.3 \pm 1.37^{a}$ \\
LT-4 & $0.326 \pm 0.021^{a}$ & $2.929 \pm 0.141^{a}$ & $128.7 \pm 7.88^{a}$ \\
LT-4+LPOH & $0.545 \pm 0.051^{b}$ & $1.877 \pm 0.195^{b}$ & $79.7 \pm 6.21^{b}$ \\
LT-4+HPOH & $0.564 \pm 0.034^{b}$ & $1.99 \pm 0.119^{b}$ & $85.6 \pm 5.69^{a b}$ \\
LT-4+CBZ & $0.541 \pm 0.046^{b}$ & $1.803 \pm 0.173^{b}$ & $70.7 \pm 3.84^{b}$ \\
\hline
\end{tabular}

Data are expressed as Mean \pm S.E.M for 10 rats /group. a: significant difference from control group at the same column with one way ANOVA at $\mathrm{P}<0.05$. b: significant difference from $\mathrm{L}-\mathrm{T}_{4}$ at the same column with one way ANOVA at $\mathrm{P}<0.05$.

Table 4: Effects of LPOH, HPOH and CBZ (as reference drug) on liver function (ALT, AST, TP, Alb, Glob, A/G) in hyperthyroidism rat model

\begin{tabular}{lcccccc}
\hline $\begin{array}{l}\text { Parameters Ani- } \\
\text { mal }\end{array}$ & AST (U/l) & ALT (U/l) & TP (g/dl) & Alb (g/dl) & Glob (g/dl) & A/G \\
$\begin{array}{l}\text { Groups } \\
\text { Control }\end{array}$ & $51.0 \pm 1.47$ & $27.6 \pm 0.74$ & $7.8 \pm 0.20$ & $3.7 \pm 0.10$ & $4.1 \pm 0.11$ & $0.90 \pm 0.025$ \\
LPOH & $47.9 \pm 1.29$ & $31.1 \pm 0.89$ & $7.2 \pm 0.19$ & $4.1 \pm 0.10$ & $3.1 \pm 0.08$ & $1.32 \pm 0.042$ \\
HPOH & $56.8 \pm 1.26^{a}$ & $33.9 \pm 0.91$ & $7.4 \pm 0.20$ & $3.9 \pm 0.10$ & $3.5 \pm 0.09$ & $1.11 \pm 0.038$ \\
LT-4 & $58.1 \pm 1.60^{a}$ & $31.7 \pm 0.48$ & $6.3 \pm 0.17^{a}$ & $3.3 \pm 0.08$ & $3.0 \pm 0.08^{a}$ & $1.10 \pm 0.023$ \\
LT-4+LPOH & $49.2 \pm 1.37^{a}$ & $29.5 \pm 0.80$ & $7.7 \pm 0.21^{b}$ & $3.8 \pm 0.10$ & $3.9 \pm 0.10^{b}$ & $0.97 \pm 0.02$ \\
LT-4+HPOH & $76.7 \pm 2.14^{a b}$ & $31.7 \pm 0.86$ & $7.6 \pm 0.20^{b}$ & $3.6 \pm 0.10$ & $4.0 \pm 0.10^{b}$ & $0.90 \pm 0.024$ \\
LT-4+CBZ & $57.5 \pm 1.62^{a}$ & $26.2 \pm 0.71$ & $8.0 \pm 0.21^{b}$ & $4.2 \pm 0.11^{b}$ & $3.8 \pm 0.10^{b}$ & $1.11 \pm 0.029$ \\
\hline
\end{tabular}

Dataare expressed as Mean \pm S.E.M for 10 rats /group. a: significant difference from control group at the same column with one way ANOVA at $\mathrm{P}<0.05$. b: significant difference from $\mathrm{L}-\mathrm{T}_{4}$ at the same column with one way ANOVA at $\mathrm{P}<0.05$. 


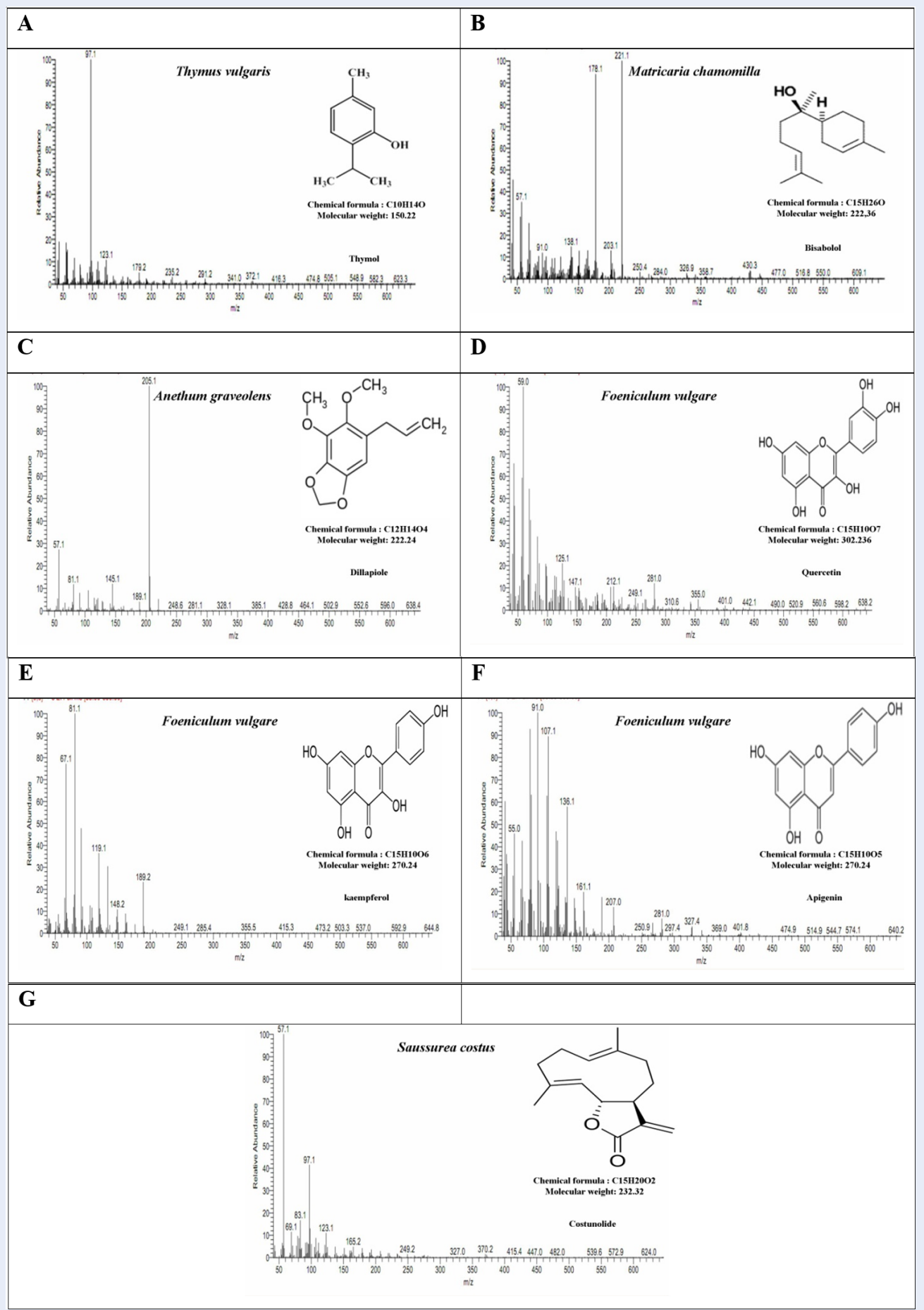

Figure 3: Gas chromatogram of the aqueous extract of POH. 
oxidized glutathione (actual mean of $1.284 \pm 0.071$, $1.184 \pm 0091$, respectively), and exhausted reduced glutathione (actual mean of $4.56 \pm 0.120$ ). On another hand, $\mathrm{LPOH}, \mathrm{HPOH}$ and $\mathrm{CBZ}$ remedy stabilized oxidative radicals with actual means of $0.647 \pm$ $0.057,0.915 \pm 0.126,0.696 \pm 0.074,0.412 \pm 0.024$, $0.486 \pm 0.033$, and $0.349 \pm 0.021$, respectively, vs. $\mathrm{LT}_{4}$ group. Moreover, there was an increase in antioxidant defense marker GSH in liver tissue $(10.50 \pm 0.366$, $8.69 \pm 0.230,11.14 \pm 0.276$, respectively, $v s \mathrm{LT}_{4}$ ).

Data obtained in Table 6shows a marked increase of cell wall degeneration via increase of MDA and DNA fragmentation via increase of its metabolites (8OHdG) for the LT4 group (means of $17.01 \pm 0.647$ and $390 \pm 11.77$, in comparison with the control group (means of $0.535 \pm 0.04,320 \pm 15.67$, respectively). In contrast, $\mathrm{LPOH}, \mathrm{HPOH}$, and $\mathrm{CBZ}$ ameliorate hepatocytes from DNA and $8 \mathrm{OHdG}$ (means of $11.31 \pm 0.200,8.91 \pm 0.337,10.81 \pm 0.437,342 \pm$ $19.83,351 \pm 15.74,365 \pm 8.17$, respectively, vs. $\mathrm{LT}_{4}$ groups.

As shown in Table 7, the $\mathrm{LT}_{4}$ treated group showed a marked decrease of the appetite brain marker (5-HT), and metabolite cell energy of liver (via potent acceleration of ATP conversion to ADP and AMP; mean of $0.210 \pm 0.013,17.5 \pm 0.87,32.1 \pm 1.053,19.0 \pm 0.797$, respectively). On the other hand, $\mathrm{LPOH}, \mathrm{HPOH}$ and $\mathrm{CBZ}$ also stimulate serotonin secretion and activate ATP; thus their actual means are $0.438 \pm 0.012,0.462$ $\pm 0.038,0.416 \pm 0.036,26.9 \pm 0.99,28.7 \pm 1.30,30.4$ \pm 0.64 , respectively, $v s$. $\mathrm{LT}_{4}$ group, which nearly ameliorated the control group.

Photomicrograph sections of group 1 (Figure 4A) showed normal histological structure of thyroid gland and there are not any pathological alterations. Group 2 (Figure 4B) demonstrates thyroid follicles of variable sizes. Thyroid follicles were lined by cubical follicular cells with rounded basophilic nuclei. Also, many follicle lumen were empty from colloid. In these groups, multiple follicular cells exhibited pale nuclei and vacuolated cytoplasm (which nearly obliterated their cavities). Atrophied of some thyroid gland follicles and minute blood capillaries were also recorded in these sections. Group 3 (Figure 4C) demonstrates that some of follicular cells lining thyroid follicles slumped inside the lumen but some of them were partially filled with colloid. The colloid of the follicular spaces exhibited peripheral vacillations. Also, the cytoplasm follicular cells revealed, clear vacuoles with pyknotic or karyolitic nuclei. In additional, the degenerated lining of cells in some of the follicles were detected in these sections. Congested blood capillaries were extended between thyroid follicles and packed with red cells before being detected. For Group 4 (Figure 4D), there were variable sizes of thyroid follicles. The lumen of the follicles contained basophilic colloid with peripheral vacillations. Also, scanty colloid was observed in most of remaining thyroid follicles. In these glands, the escape of blood from capillaries was recorded. In order to avoid this, we found that there was an increase in lining cells number of follicles compared to the previous group. Group 5 (Figure 4E) demonstrated thyroid follicles showed uniformly distributed variable size with little number of follicles with single layered flattened epithelium filled with abundant colloid. The lumen of follicles contained uniformly distributed colloid with peripheral vacillations. In these thyroid glands, the hydrophobic degeneration changes were seen in some follicles. The congested blood capillaries were still observed in these sections. In group 6 (Figure $4 F$ ), there was a demonstrated clear vacuolation of the follicular colloid. Some of follicular cells were increased in size with deeply basophilic nuclei. Also, the layers of follicles were distributed from thin to thick of epithelium cells. Finally, the congested blood vessels were still noted. In group 7 (Figure 4G), there was an increased number of thyroid follicles compared to the previous groups. The follicles exhibit peripheral and central colloidal vacillations. Moreover, vacuolation of the cytoplasm of the follicular cells with karyolitic nuclei were occasionally seen.

\section{DISCUSSION}

The current study showed that there was a significant increase in serum T3 and T4 levels, as well as a significant decrease in serum TSH level in rats treated with L-thyroxin, when compared to the control, $\mathrm{POH}$ and drug groups. This indicates that $\mathrm{LT}_{4}$ was convenient for induction of HT.

$\mathrm{LT}_{4}$ stimulates thyroid activity and exerts its primary effect on the synthesis of the thyroid hormones, thyroxin and triiodothyronine by blocking oxidative iodination within the thyroid gland itself. In addition, L-thyroxin triggers the metabolism of THs outside of thyroid gland by interfering with the peripheral deiodination of $\mathrm{T}^{23}$. The decrease in $\mathrm{TSH}$ secretion by the anterior pituitary gland extends a negative feedback effect on thyroid gland secretion of T3 and T4. Obtained data of $\mathrm{POH}$ showed that flavonoids may influence on thyroid function through reduction of thyroid peroxidase activity. These effects may be due to flavonoids of $\mathrm{POH}$ constituents, such as dillapiole, costunolide and caffeic acid, on the thyroid function, which is more pronounced when iodine is deficient ${ }^{24}$. Other flavonoids, such as kaempferol and 
Table 5: Effects of LPOH, HPOH and CBZ (as reference drug) on oxidative stress markers (NO, GSH, GSSG) in hyperthyroidism rat model

\begin{tabular}{lccc}
\hline $\begin{array}{l}\text { Parameters } \\
\text { Animal } \\
\text { Groups }\end{array}$ & NO $(\mu \mathrm{g} / \mathbf{g}$ tissue $)$ & GSH $(\mu \mathbf{g} / \mathbf{g}$ tissue $)$ & GSSG $(\mu \mathbf{g} / \mathbf{g}$ tissue $)$ \\
Control & $0.535 \pm 0.04$ & & \\
LPOH & $0.611 \pm 0.039^{a}$ & $10.41 \pm 0.276$ & $0.394 \pm 0.019$ \\
HPOH & $0.728 \pm 0.083^{a}$ & $10.92 \pm 0.281$ & $0.389 \pm 0.028$ \\
LT-4 & $1.284 \pm 0.071^{a}$ & $8.34 \pm 0.187$ & $0.461 \pm 0.034^{a}$ \\
LT-4+LPOH & $0.647 \pm 0.057^{a b}$ & $10.56 \pm 0.120^{a}$ & $1.184 \pm 0091^{a}$ \\
LT-4+HPOH & $0.915 \pm 0.126^{a b}$ & $8.69 \pm 0.230^{b}$ & $0.412 \pm 0.024^{b}$ \\
LT-4+CBZ & $0.696 \pm 0.074^{a b}$ & $11.14 \pm 0.276^{b}$ & $0.486 \pm 0.033^{a b}$ \\
\hline
\end{tabular}

Data are expressed as Mean \pm S.E.M for 10 rats /group. a: significant difference from control group at the same column with one way ANOVA at $\mathrm{P}<0.05$. b: significant difference from $\mathrm{L}-\mathrm{T}_{4}$ at the same column with one way ANOVA at $\mathrm{P}<0.05$.

Table 6: Effects of LPOH, HPOH and CBZ (as reference drug) on cell degeneration markers (MDA, 8OHdG) in hyperthyroidism rat model

\begin{tabular}{lcc}
\hline $\begin{array}{l}\text { Parameters } \\
\text { Animal } \\
\text { Groups }\end{array}$ & MDA (nmol/g tissue) & 8OHdG (pg/g tissue) \\
Control & $10.62 \pm 0.405$ & \\
LPOH & $10.31 \pm 0.124$ & $320 \pm 15.67$ \\
HPOH & $13.34 \pm 0.311$ & $297 \pm 14.51$ \\
LT-4 & $17.01 \pm 0.647^{a}$ & $328 \pm 14.66$ \\
LT-4+LPOH & $11.31 \pm 0.200^{b}$ & $390 \pm 11.77^{a}$ \\
LT-4+HPOH & $8.91 \pm 0.337^{b}$ & $342 \pm 19.83^{a b}$ \\
LT-4+CBZ & $10.81 \pm 0.437^{b}$ & $351 \pm 15.74^{a b}$ \\
\hline
\end{tabular}

Data are expressed as Mean \pm S.E.M for 10 rats /group. a: significant difference from control group at the same column with one way ANOVA at $\mathrm{P}<0.05$. b: significant difference from $\mathrm{L}-\mathrm{T}_{4}$ at the same column with one way ANOVA at $\mathrm{P}<0.05$.

Table 7: Effects of $\mathrm{LPOH}, \mathrm{HPOH}$ and CBZ (as reference drug) on apetite marker (5HT), and cell energy markers (ATP, ADP, AMP) in hyperthyroidism rat model

\begin{tabular}{|c|c|c|c|c|}
\hline $\begin{array}{l}\text { Parameters } \\
\text { Animal } \\
\text { Groups }\end{array}$ & 5HT ( $\mu$ g/g tissue $)$ & ATP $(\mu \mathrm{g} / \mathrm{g}$ tissue $)$ & $\operatorname{ADP}(\mu \mathrm{g} / \mathrm{g}$ tissue $)$ & AMP $(\mu \mathrm{g} / \mathrm{g}$ tissue $)$ \\
\hline Control & $0.507 \pm 0.02$ & $28.0 \pm 1.38$ & $20.1 \pm 0.658$ & $11.9 \pm 0.498$ \\
\hline $\mathrm{LPOH}$ & $0.489 \pm 0.022$ & $30.5 \pm 0.78$ & $20.8 \pm 0.712$ & $12.9 \pm 0.389$ \\
\hline $\mathrm{HPOH}$ & $0.524 \pm 0.024$ & $33.9 \pm 0.90$ & $23.4 \pm 1.190$ & $13.2 \pm 0.544$ \\
\hline LT-4 & $0.210 \pm 0.013^{a}$ & $17.5 \pm 0.87^{a}$ & $32.1 \pm 1.053^{a}$ & $19.0 \pm 0.797^{a}$ \\
\hline LT-4+LPOH & $0.438 \pm 0.012^{b}$ & $26.9 \pm 0.99^{b}$ & $17.9 \pm 0.493$ & $11.2 \pm 0.608$ \\
\hline LT-4+HPOH & $0.462 \pm 0.038^{b}$ & $28.7 \pm 1.30^{b}$ & $19.2 \pm 0.660$ & $9.2 \pm 0.414$ \\
\hline LT-4+CBZ & $0.416 \pm 0.036^{b}$ & $30.4 \pm 0.64^{b}$ & $19.1 \pm 0.793$ & $10.6 \pm 0.500$ \\
\hline
\end{tabular}

Data are expressed as Mean \pm S.E.M for 10 rats /group. a: significant difference from control group at the same column with one way ANOVA at $\mathrm{P}<0.05$. b: significant difference from $\mathrm{L}-\mathrm{T}_{4}$ at the same column with one way ANOVA at $\mathrm{P}<0.05$. 


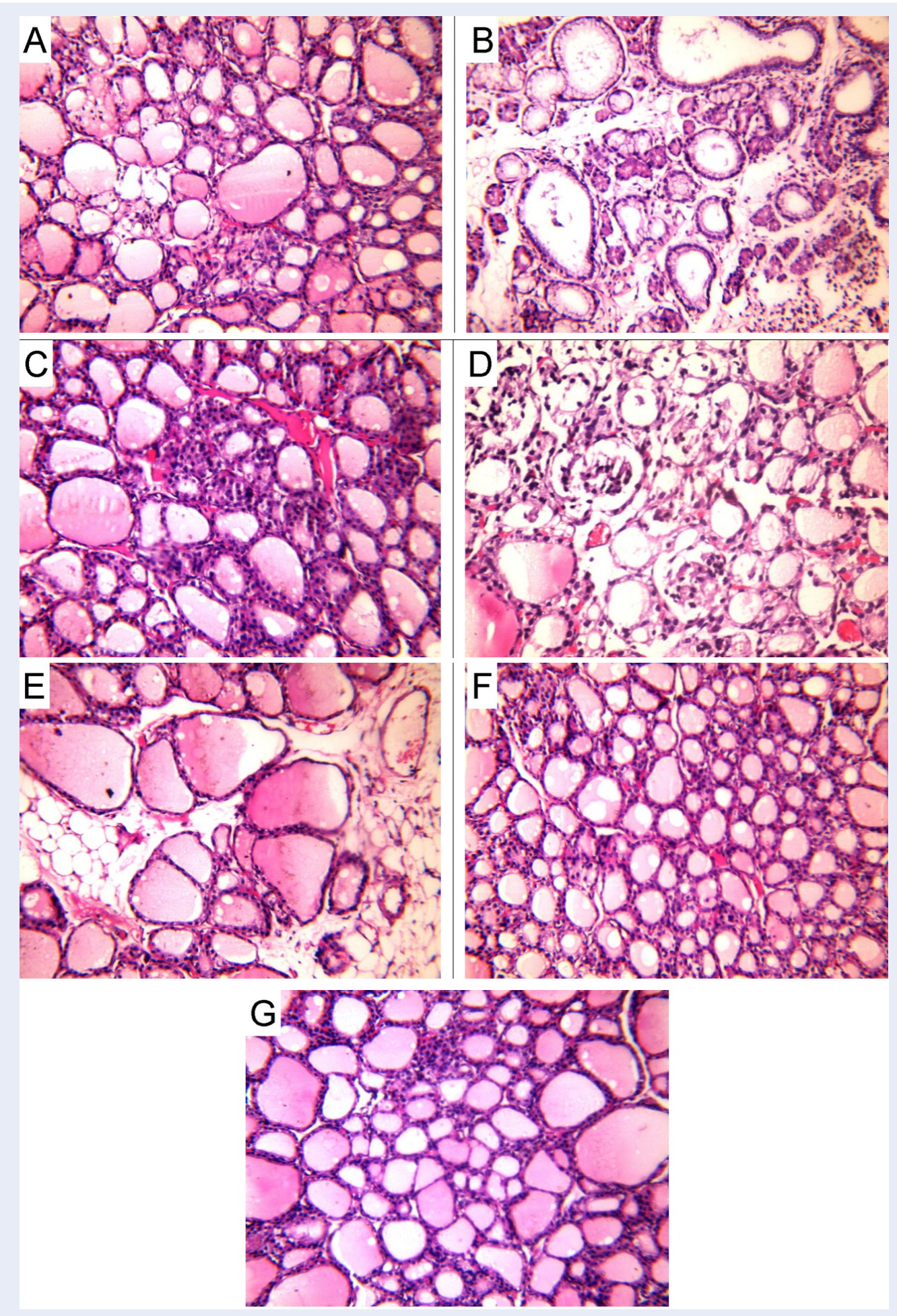

Figure 4: Histopathological examination of thyroid gland treated with POH at hyperthyroidism rat model. 
quercetin, were also shown to irreversibly inhibit thyroid peroxidase. Another pathway for decreasing HT in our model may due to tannins included in $\mathrm{POH}$, such as gallic acid and epigallocatechin gallate, which act as a chelating agent through bonding with inorganic iodide. Subsequently, the correction of iodine deficiency leads to normalization of THs. Indeed, THs were positively correlated with flavonoid ingestion owing to the biosynthesis of T4 confined to thyroid gland. The majority of THs are T3 (80\%), and synthesized in the liver (out of the thyroid). Each of the pathways has illustrated that polyphenolic compounds may affect the thyroid gland but not other organs $^{25}$.

Hyperthyroidism is still not yet fully elucidated. Induction of lipid peroxidation but indirect pathways may be responsible for some complications, such as various biochemical changes leading to cell damage. In our study, we investigated the role of $\mathrm{POH}$ on liver function to verify possible beneficial effects without side effects. Our results showed mild alteration of liver function, increase leakage of enzyme, and decrease of protein production (though not significant). In contrast, oxidative stress markers (such as MDA, NO, GSSG, and 8OHdG) were positively increased and were associated with hyperthyroidism, compared with the control group. This association may be due to increase of mitochondrial respiration from an imbalance of metabolic hormones. Increased respiration increases reductive and intrusive status, leading to cell wall damage; stimulation of extreme MDA and $8 \mathrm{OHdG}$ production and decrease of GSH can occur, leading to greater production of GSSG ${ }^{26}$. Amelioration of oxidative stress markers for $\mathrm{POH}$ may be due to reachable amounts of flavonoids, especially ascorbic acid and quercetin, which help prevent liver damage, hypercholesterolemia, atherosclerosis, and heart failure. A recent study demonstrated that quercetin has potent ROS scavenging activity due to the high number of hydroxyl substitutions ${ }^{27}$. In the present study, $\mathrm{POH}$ enriched quercetin and, thus, played a therapeutic role by reducing liver oxidative enzyme activity while decreasing lipid peroxidation.

The data obtained in our study illustrate that increase of ATP turnover subsequently increases ADP and AMP, and decreases ATP concentration in liver tissues due to excessive production of THs. Certainly, $\mathrm{POH}$ is an active treatment which may ameliorate thyroxin over secretion via tannins, caffeic acid and galic acid, and can act as a chelating agent of iodine liberated in the bloodstream ${ }^{28}$. According to thyroxin oversecretion and recovery of $\mathrm{POH}$, most subsequent parameters were ameliorated near to control (normal) group. In the same way, liver cell energy was acclimatization and sedation of metabolic hyper activity. The synergetic effects of quercetin and ferulic acid may ameliorate the side effects of thyroid over secretion due to total antioxidant capacity and their antioxidant properties. Recent studies have reported that quercetin acts as a tranquilizer agent in hyperactive rats $^{29}$. 5-HT can increase and ameliorate subsequent hyperactivity after thyroxin elevation from insomnia or anxiety.

On the whole, herbal extract is a new direction for exchange of chemical drugs due to its side effects and unknown interactions. Indeed, $\mathrm{POH}$ containing mixture of flavonoids and tannins have stabilized the most common side effect of hyperthyroidism- via stimulating different pathways whether internal or external cell processes. The internal pathway may be due to succinate dehydrogenase inhibitor and $\mathrm{Na} / \mathrm{k}$ - ATPase inhibitor, according to epigallocatechin gallate content. External pathway may be due to iodine trapping, suppression of chemotactic factors, and suppression of reductive markers, which due to the phenolic component contribute to the synergetic action $^{30}$.

In the present study, alterations in thyroid function after $\mathrm{LT}_{4}$ exposure were confirmed by the histological examination of the thyroid follicles by H\&E. Our hyperthyroidism model-induced by $\mathrm{LT}_{4}$ - showed histological changes which may be due to TSH suppression. It is well-known that low levels of TSH affect thyroid gland function and structure. On the other hand, normal levels have yielded simulative effects on the follicles, which are modulated by the action of a variety of molecules, such as peptides and/or neuropeptides, derived from para follicular cells and other growth factors. The hyperthyroidism model demonstrated that follicles have irregular shape and many cubical follicular cells are lined with basophilic nuclei accompanied by empty luminal colloids. Also, multiple follicular cells exhibited pale nuclei, vacuolated cytoplasm and nearly obliterated their activities. Takamatsu et al. illustrated irregular and atrophied follicles shaped with $\mathrm{LT}_{4}$, which induced hyperthyroidism modulated condensed nuclei walls and follicle loss of thyroid gland ${ }^{31}$.

$\mathrm{POH}$ showed increased of columnar follicular cells size, vacuolated cells and deeply stained nuclei. The findings of $\mathrm{POH}$ may be owing to the accumulation of fluid and glands over stimulation. Therefore, the increase in TSH threshold in a $\mathrm{POH}$-treated hyperthyroid model could be the causative factor for rebuilding cells and follicles, and could regenerate thyroid hypertrophy and increase cell size and functional capacity for normal status ${ }^{32}$. 
According to the reference drug for treating the hyperthyroidism model, CBZ showed the variable size of follicles filled with abundant colloid. These disruptions may be due to the hydrophobic degeneration changes and minute blood capillaries extended between them. Also, proliferation of parenchyma was shown, which led to increased interfollicular space and delayed TSH for T3 and T4.

\section{CONCLUSION}

The findings of the study suggest that an anti-thyroid compound, equal in potency to herbal plants and natural products, has been isolated from the root, leaf and seed of those various plants. Alternative thyroid treatments place more importance on improving lifestyles and nutritional diet, providing spiritual support along with natural thyroid medication and also place priority on improving functions of other organs that increase thyroid performance. Still various herbal plants that were questionable need to be further studied.

\section{COMPETING INTERESTS}

The authors report no conflicts of interest in this work.

\section{AUTHORS' CONTRIBUTIONS}

Sahar Ahmed, Asmaa Moghazy and Omar Farid designed the study and per-formed the experiments and con-ducted the data analysis, Sahar. Ahmed. Asmaa Moghazy and Omar Farid participated in drafting the paper, wrote the manuscript and approved the manuscript. Hassan A. Esebery prepares and reported the histopathology.

\section{ACKNOWLEDGMENTS}

The authors are thankful to Dr. Mohamed Mahmoud Seif, Toxicology and Food contaminants Department, Food Industry and Nutrition Division, National Research Center, 33 El-Bohouth St., P.O. 12622, Dokki, Giza, Egypt, for the kind help in GCMS analysis for herbal extraction.

\section{ABBREVIATION \\ 5HT: Serotonin \\ 8OHdG: 8-hydroxy-2' -deoxyguanosine \\ ADP: Adenosine diphosphate \\ ALT: Alanine aminotransferase \\ AMP: Adenosine monophosphate \\ AST: Aspartate aminotransferas \\ ATP: Adenosine triphosphate \\ b.w.: Body weight \\ CBZ: Carbimazole}

GSH: Reduced glutathione

GSSG: Oxidized glutathione

HPOH: High dose of poly herb

HT: Hyperthyroidism

LPOH: Low dose of Poly herb

MDA: Malondialdehyde

NO: Nitric oxide

POH: Poly herb

T3: Triiodothyronine

T4: Thyroxin

TPO: Thyroid peroxidases

TRH: Thyroid releasing hormone

TSH: Thyroid-stimulating hormone

\section{REFERENCES}

1. Tortora GJ, Derrickson B. Principles of anatomy and physiology; 2012.

2. IFS. Human Physiology. In: Human Physiology. Mc Graw Hill; 2010. .

3. Porterfield SP, Hendrich CE. The role of thyroid hormones in prenatal and neonatal neurological development-current perspectives. Endocrine Reviews. 1993;14:94-106.

4. Glinoer D. The regulation of thyroid function in pregnancy: pathways of endocrine adaptation from physiology to pathology. Endocrine Reviews. 1997;18:404-33. Available from: DOI:10.1210/edrv.18.3.0300.

5. Tu HM, Legradi G, Bartha T, Salvatore D, Lechan RM, Larsen PR. Regional expression of the type 3 iodothyronine deiodinase messenger ribonucleic acid in the rat central nervous system and its regulation by thyroid hormone. Endocrinology. 1999;140:784-90. Available from: DOI:10.1210/endo.140. 2.6486.

6. Bahn RS, Burch HS, Cooper DS, Garber JR, Greenlee CM, Klein $\mathrm{IL}$. The role of propylthiouracil in the management of Gravesdisease in adults: report of a meeting jointly sponsored by the American Thyroid Association and the Food and Drug Administration. Thyroid. 2009;19:673-4. Available from: DOI: 10.1089/thy.2009.0169.

7. Putra A, Riahi S. The Simultaneous Effects of some Herbal Mixtures on Methimazole Medicine for Thyroide Treatment. Medbiotech Journal. 2018;2:111-116.

8. Nogata Y, Ohta H, Yoza Kl, Berhow M, Hasegawa S. Highperformance liquid chromatographic determination of naturally occurring flavonoids in Citrus with a photodiode-array detector. Journal of Chromatography A. 1994;667:59-66. Available from: Doi:10.1016/0021-9673(94)89051-x.

9. Wang Y, Li S, Han D, Meng K, Wang M, Zhao C. Simultaneous determination of rutin, luteolin, quercetin, and betulinic acid in the extract of Disporopsis pernyi (Hua) Diels by UPLC. Journal of analytical methods in chemistry. 2015;2015.

10. Tokusoglu O, Unal MK, Yildirim Z. HPLC-UV and GC-MS characterization of the flavonol aglycons quercetin, kaempferol, and myricetin in tomato pastes and other tomato-based products. Acta Chromatographica. 2003;13:196-207.

11. Fisher DA. Physiological variations in thyroid hormones: physiological and pathophysiological considerations. Clinica Chemistry. 1996:42:135-9.

12. Thakur C, Saikia TC, Yadav RN. Total serum levels of triiodothyronine (T3) thyroxine (T4) and thyrotropine (TSH) in school going children of Dibrugarh district: an endemic goitre region of Assam. Indian Journal of Physiology and Pharmacology. 1997:41:167-70.

13. Reitman S, Frankel S. A colorimetric method for the determination of serum glutamic oxalacetic and glutamic pyruvic transaminases. American Journal of Clinical Pathology. 1957;28:56-63. Available from: DOI:10.1093/ajcp/28.1.56. 
14. Gornall AG, Bardawill CJ, David MM. Determination of serum proteins by means of the biuret reaction. The Journal of Biological Chemistry. 1949;177:751-66.

15. Doumas BT, Watson WA, Biggs HG. Albumin standards and the measurement of serum albumin with bromcresol green. Clinica Chimica Acta. 1971;31:87-96. Available from: Doi:10. 1016/0009-8981(71)90365-2.

16. Karatepe M. Simultaneous determination of ascorbic acid and free malondialdehyde in human serum by HPLC-UV. LC GC North America. 2004;22:362-5.

17. Jayatilleke $E$, Shaw S. A high-performance liquid chromatographic assay for reduced and oxidized glutathione in biological samples. Analytical Biochemistry. 1993;214:452-7. Available from: DOI:10.1006/abio.1993.1522.

18. Papadoyannis IN, Samanidou VF, Nitsos CC. Simultaneous determination of nitrite and nitrate in drinking water and human serum by high performance anion-exchange chromatography and UV detection. Journal of liquid chromatography \& related technologies. 1999;22:2023-2041.

19. Lodovici M, Casalini C, Briani C, Dolara P. Oxidative liver DNA damage in rats treated with pesticide mixtures. Toxicology. 1997;117:55-60. Available from: Doi:10.1016/s0300-483x(96) 03553-6.

20. Teerlink T, Hennekes M, Bussemaker J, Groeneveld J. Simultaneous determination of creatine compounds and adenine nucleotides in myocardial tissue by high-performance liquid chromatography. Analytical Biochemistry. 1993;214:278-83. Available from: DOI:10.1006/abio.1993.1488.

21. Pagel P, Blome J, Wolf HU. High-performance liquid chromatographic separation and measurement of various biogenic compounds possibly involved in the pathomechanism of Parkinsonś disease. Journal of Chromatography B, Biomedical Sciences and Applications. 2000;746:297-304. Available from: Doi:10.1016/s0378-4347(00)00348-0.

22. Banchroft JD, Stevens A, Turner DR. Theory and practice of histological technique; 1996.

23. Mullur R, Liu YY, Brent GA. Thyroid hormone regulation of metabolism. Physiological Reviews. 2014;94:355-82. Available from: DOI:10.1152/physrev.00030.2013.
24. Divi RL, Doerge DR. Inhibition of thyroid peroxidase by dietary flavonoids. Chemical Research in Toxicology. 1996;9:16-23. Available from: DOI:10.1021/tx950076m.

25. Ali NI. Determination of the normal range of thyroid hormones in Sudanese by locally produced reagents. 1999;

26. Nishiki K, Erecinska M, Wilson DF, Cooper S. Evaluation of oxidative phosphorylation in hearts from euthyroid, hypothyroid, and hyperthyroid rats. The American Journal of Physiology. 1978;235:C212-9. Available from: DOI:10.1152/ajpcell. 1978.235.5.C212.

27. Mira L, Fernandez MT, Santos $M$, Rocha R, Florencio $M H$, Jennings KR. Interactions of flavonoids with iron and copper ions: a mechanism for their antioxidant activity. Free Radical Research. 2002;36:1199-208. Available from: Doi:10.1080/ 1071576021000016463.

28. Peleg $\mathrm{H}$, Bodine KK, Noble AC. The influence of acid on astringency of alum and phenolic compounds. Chemical Senses. 1998:23:371-8. Available from: DOI:10.1093/chemse/23.3.371.

29. Okamura K, Sato K, Yoshinari M, Ikenoue H, Kuroda $T$, Nakagawa M. Recovery of the thyroid function in patients with atrophic hypothyroidism and blocking type TSH binding inhibitor immunoglobulin. Acta Endocrinologica. 1990;122:107-14. Available from: DOI:10.1530/acta.0 1220107.

30. Moreira OC, Rios PF, Barrabin H. Inhibition of plasma membrane $\mathrm{Ca}(2+)$-ATPase by CrATP. LaATP but not CrATP stabilizes the $\mathrm{Ca}(2+)$-occluded state. Biochimica et Biophysica Acta. 2005;1708:411-9. Available from: DOI:10.1016/j.bbabio.2005 05.010 .

31. Takamatsu J, Takeda K, Katayama S, Sakane S, Morita S Kuma K. Epithelial hyperplasia and decreased colloid content of the thyroid gland in triiodothyronine-predominant Gravesdisease. The Journal of Clinical Endocrinology and Metabolism. 1992;75:1145-50.

32. Doganay L, Puyan FO, Oz F, Ergul Z, Bilgi S, Ekuklu G. Regenerative hyperplasia of follicular epithelium in chronic lymphocytic thyroiditis. Applied Immunohistochemistry \& Molecular Morphology. 2005;13:353-7. 